\title{
Sağlık Yapılarının İklimsel Konfor Tasarım Parametrelerine Göre Değerlendirilmesi: "Soğuk İklim Bölgesinden Muş Devlet Hastanesi Örneği”
}

\author{
Örge Gizem ÇALIŞ ${ }^{\star 1}$, Mehmet Zafer AKDEMiR ${ }^{2}$
}

\section{ÖZET}

Yapılan araştırmalar enerji tüketiminin büyük bir bölümünün yapılardan kaynaklandığını göstermektedir. Enerjinin yenilenemeyen kaynaklardan elde edilmesi ile enerji harcamaları artmaktadır. Bu durum kaynakların giderek azalmasına ve ekolojik dengenin bozulmasına neden olmaktadır. Yapılarda tüketilen enerjinin azaltılması ve enerji kullanımının verimli hale getirilmesi, sürdürülebilir çevre oluşturmanın temel adımlarından biri haline gelmiştir. Sağlık yapıları, kompleks tipolojileri ve teknik donanımlarıyla diğer kamu yapılarına oranla daha yüksek miktarlarda enerji tüketiminin gerçekleştiği yapı türleridir. Sağlık yapılarının enerji maliyetlerinin azaltılmasına, finansal kaynaklarının etkin ve verimli kullanılmasına katkıda bulunmak bir takım kararlar ile mümkün olabilmektedir. Bu bağlamda, tasarım aşamasında alınacak kararların etkisini değerlendirmek üzere bir çalışma yürütülmüştür.

Bu çalışmada, Türkiye'nin soğuk iklim bölgesinde bulunan Muş Devlet Hastanesi için, bölgenin iklim özellikleri gözetilmeden verilen kararların iklimsel konfor tasarım parametreleri üzerinden değerlendirmesi yapılmıştır. Muş Devlet Hastanesi Sağlık Bakanlığı'nın denetiminde, "Sağlıkta Dönüşüm Projesi" çerçevesinde, değişen sağlık politikaları kapsamında uygulanmış bir sağlık yapısıdır. Ayrıca, sağlık yapılarının enerji etkinliğine yönelik bölgesel farklılıkların dikkate alınarak iklimle dengeli tasarlanmasının önemi ve gerekliliği incelenmiştir.

Anahtar kelimeler: Sağlık Yapıları, İklimsel Konfor, İklime Duyarlı Tasarım

\section{Evaluation of Climatic Comfort Design Parameters in Healthcare Facilities: "Muş State Hospital Sample From Cold Climate Region"}

\begin{abstract}
Researches betray the fact that building stock is responsible for large part of energy consumption. Energy expenditures are increasing as energy is derived from nonrenewable sources. This situation leads to a gradual decrease in resources and deterioration of ecological balance. Reducing the amount of energy consumed by the buildings and making energy usage more efficient have become one of the basic strategies in creating a sustainable environment. Complex typologies and technical equipment of health facility are the types of buildings where energy consumption takes place in higher amounts than in other public buildings. Reducing the energy costs of

\footnotetext{
${ }^{1}$ Yıldız Teknik Üniversitesi, Fen Bilimleri Enstitüsü, Yapı Bilim Dalı, Yüksek Lisans Öğrencisi

${ }^{2}$ Yard. Doç. Dr., Yıldız Teknik Üniversitesi, Fen Bilimleri Enstitüsü, Yapı Bilim Dalı, Mimarlık Bölümü,

* IIlgili yazar / Corresponding author: Örge Gizem ÇALIŞ, orge.k@hotmail.com, 05352489898

Gönderim Tarihi: 28.04.2017

Kabul Tarihi: 14.08.2018
} 
healthcare facilities and contributing to the efficient use of financial resources are possible through a number of decisions.

In this study, for Turkey, "Muş State Hospital" in the cold climate of the region's climate assesment through design parameters of climatic comfort without considering the decision is made. Muş State Hospital is a health facility under the supervision of the Ministry of Health and implemented within the scope of "Health Transformation Project" changing health policies. In addition, the importance and necessity of balanced design of climate by taking into account regional differences in energy efficiency of healthcare facilities has been examined.

Keywords: Healthcare Facilities, Climatic Comfort, Sensitive Design to the Climate

\section{GiRiş}

Bilimsel araştırmalar dünya ikliminin, insan faaliyetleri sonucunda ortaya çıkan sera gazlarının etkisiyle hızla değiştiğini göstermektedir (Bilec, Geary, Ries, Neddy ve Cashion, 2010, s. 5). Sera gazlarının bilinçsiz tüketimi sonucunda çevreye oldukça zarar veren bir durum ortaya çıkmaktadır (Hoşgör, 2014, s. 76; Yıldız, 2016, s. 325). Kaynak tüketiminin öneminin kavrandığı, çevreye duyarlı, sürdürülebilir, iklimle dengeli tasarımların oluşturulması ancak enerjinin etkin ve verimli kullanılması ile mümkündür.

İklimle dengeli tasarım çalışmalarının en önemli koşullarından biri sürdürülebilir mimarlıktır. Sürdürülebilirlik, yapı için belirleyici bir kriter olup, aynı zamanda doğaya saygılı ve akılcı yaklaşımlar ile gelecek nesillerin yaşamlarını devam ettirebilmelerinde gerekli koşulların tamamıdır. Ancak 'Sürdürülebilirlik' kavramı genellikle enerji tüketimi ve çevre duyarlıı̆̆ı konuları ile iç içe ele alınmaktadır. Oysa yapıların sürdürülebilirlik anlamında akıllı yapı olarak tasarlanması, mimarlığın ön koşullarından biridir. Akılı yapı, üzerinde barındırdığı teknolojik donanımdan çok daha fazlası, yerine, yönüne ve bağlamına gösterdiği duyarlııı, tasarım aracılığı ile sağladığı yapım ve işletme verimliliği ile ölçülmektedir. "Akıllı yapı" kavramı ile "sürdürülebilir yapı", "iklimle dengeli yapı", "iklimsel konforlu yapı" ve "yüksek performanslı yapı" gibi bazı kavramlar benzer anlamlar içermektedir (Royal Jubilee Hospital Patient Care Centre Project, 2008).

2003 yılında yayınlanan "Sağlıkta Dönüşüm Projesi" ile birlikte sağlık yapılarının hızla arttığı görülmektedir. Sağlık Bakanlığı Sağlık Araştırmaları Genel Müdürlüğü tarafından yayınlanmış Sağlık İstatistikleri Yılığı 2016 Haber Bülteni verileri incelendiğinde Sağlık Bakanlığı'na bağlı 2003 yılı öncesinde toplam 107.394 yatak kapasiteli 774 Devlet Hastanesi bulunmaktadır. 2016 yılında ise, toplam 132.921 yatak kapasiteli 876 Devlet Hastanesi bulunmaktadır. Sağlık Bakanlığı'nın hazırlamış olduğu 2012/6 sayılı genelgenin ana eksenini düşük enerji kullanımı hedefi oluşturmaktadır (Sağlık Bakanlığı, 2012). Ancak (Çizelge 1)'de belirtilen Enerji Bakanlığı referans göstergeleri incelendiğinde, sağlık yapıları alışveriş merkezlerinden sonra en fazla enerjiyi tüketen $\left(600 \mathrm{kwh} / \mathrm{m}^{2}\right.$-yıl) yapılar olarak nitelendirilmiştir. 


\begin{tabular}{|c|c|c|c|c|c|}
\hline $\begin{array}{l}\text { Yapı } \\
\text { Tipleri }\end{array}$ & $\begin{array}{l}\text { Kullanım } \\
\text { Amaçları }\end{array}$ & $\begin{array}{l}\text { 1.Isıtma } \\
\text { Bölgesi } \\
\text { (RG) }\end{array}$ & $\begin{array}{l}\text { 2.Isıtma } \\
\text { Bölgesi } \\
(R G)\end{array}$ & $\begin{array}{l}\text { 3.Isıtma } \\
\text { Bölgesi } \\
\text { (RG) }\end{array}$ & $\begin{array}{l}\text { 4.Isıtma } \\
\text { Bölgesi } \\
\text { (RG) }\end{array}$ \\
\hline \multirow[t]{2}{*}{ Konutlar } & $\begin{array}{l}\text { Tek ve } \\
\text { İkiz Aile } \\
\text { Evleri }\end{array}$ & 165 & 240 & 285 & 420 \\
\hline & $\begin{array}{l}\text { Apartman } \\
\text { Blokları }\end{array}$ & 180 & 255 & 300 & 435 \\
\hline \multirow[t]{3}{*}{$\begin{array}{l}\text { Hizmet } \\
\text { Binalar }\end{array}$} & $\begin{array}{l}\text { Ofis ve } \\
\text { Büro } \\
\text { Binaları }\end{array}$ & 240 & 300 & 360 & 495 \\
\hline & $\begin{array}{l}\text { Eğitim } \\
\text { Binaları }\end{array}$ & 180 & 255 & 300 & 450 \\
\hline & $\begin{array}{l}\text { Sağlık } \\
\text { Binaları }\end{array}$ & 600 & & & \\
\hline \multirow[t]{2}{*}{$\begin{array}{l}\text { Ticari } \\
\text { Binalar }\end{array}$} & $\begin{array}{l}\text { Otel, } \\
\text { Motel, vb. }\end{array}$ & 540 & & & \\
\hline & $\begin{array}{l}\text { Alışveriş } \\
\text { Ve Ticaret } \\
\text { Merkezleri }\end{array}$ & 750 & & & \\
\hline
\end{tabular}

(RG: Birincil Enerji cinsinden referans göstergesi, $\mathrm{kWh} / \mathrm{m}^{2}$ - yıl)

Farklı kaynaklardan yapılan araştırmalar da, sağlık yapılarının aynı büyüklükteki bir ofis binasına göre 2-2,5 kat (Paço, 2015, s. 344), bir konut binasına göre de 3 kat daha fazla enerji harcamakta olduğunu göstermektedir (Somali, 2013b, s. 2). Bu yüksek enerji tüketimi, artan maliyetleri de beraberinde getirmektedir (Bednarz, 2008, s.16).

Yapılarda tüketilen enerjinin kontrolünü sağlamak amacıyla uluslararası alanda yasal ve yönetsel düzenlemeler oluşturulmuştur. Özellikle Amerika ve Almanya gibi gelişmiş ülkelerde bu düzenlemeler ile ciddi ilerlemeler kaydedilmiştir. Yasal ve yönetsel düzenlemelerdeki ortak nokta, yapıların yenilenebilir enerji kaynakları kullanılarak tasarlanmalarıdır. Carpenter ve Hoppszallern (2010), sağlık yapılarının sürdürülebilirlik bağlamında ele alınmasında ilk adımın, enerji yönetimi olduğunu belirtmişlerdir. Maksimum enerji tüketimi olan alanların belirlenmesi önem arz eder (Carpenter ve Hoppszallern, 2010, s. 16-17). Bu bağlamda, daha tasarım aşamasında, iklimsel konfor koşullarının sağlandığı parametrelerin benimsenerek, yapının konum, yönlendirilme, form, kabuk ve yakın çevre yapılaşma düzeniyle uyum içerisinde olduğu seçeneklerin belirlenmesi ve uygulamasının yapılması gerekmektedir.

Sağlık Bakanlığı 2003 yılı sonrasında "Sağlıkta Dönüşüm Projesi" çerçevesinde sağıık yapıları tasarımında yeni düzenlemeler getirmiştir. Söz konusu düzenlemeler ile modern sağlık yapıları tasarımı hedeflenmiştir. Çağdaş tasarım pratiklerini içeren projeler ile iklimle dengeli tasarımlar oluşturmak proje kapsamında yayınlanan standartlar ve yönetmelikler ile mümkün olabilmektedir.

Çalışmanın amacı, Türkiye'nin soğuk iklim bölgesinde bulunan, 2003 yılı sonrasında "Sağlıkta Dönüşüm Projesi" çerçevesinde Sağlık Bakanlığı denetiminde kamu eliyle uygulanmış bir yapı olan "Muş Devlet Hastanesi" üzerinden sağlık yapılarının iklimsel konfor tasarım parametreleri bağlamında sorgulanmasıdır.

\section{YÖNTEM}


Bu çalışma, üç bölümden oluşmaktadır. Ön çalışmada, sağlık yapılarının iklimle dengeli tasarımı noktasındaki problemlere ilişkin önemli yazılı kaynaklar, mimari projeler ve proje uygulamaları incelenmiştir. Çalışmanın araştırma kısmında ise seçilmiş olan örnek üzerinden proje firması, müşavir firma, yüklenici firma ve Sağlık Bakanlığı'ndan temin edilen yazılı ve görsel kaynaklardan yararlanılmıştır. Araştırmalar sonucunda parametreler belirlenmiştir. Her bir parametre ayrı ayrı değerlendirilerek çizelge yardımıyla anlatımı yapılmıştır. Çalışmanın sonucunda, ön çalışma kısmında taranan belgelerden elde edilen bilgilerin analizi yapılarak incelenen Muş Devlet Hastanesi'nin iklim bölgesi ayrımı dikkate alınmaksızın belirlenen tasarım kararlarının etkileri ortaya konulmuştur.

\section{3. İKLIMSEL KONFOR TASARIM PARAMETRELERI}

Sağlık ve iklimsel konfor gibi kavramların bir bütün olarak karşılandığı İklimle dengeli tasarımların oluşturulması sağlık yapıları için son derece önemlidir. Bu kavramlar;

"Sağlık", Dünya Sağlık Örgütü'nün tanımına göre yalnızca hastalık olmaması değil, fiziksel ruhsal ve sosyal refaha sahip olma halidir (WHO)

"İklimsel Konfor", belirli bir eylemi yapmakta olan canlının, bedensel ve zihinsel performans noktasında en az enerji ile istenen düzeydeki eylemini gerçekleştirebilme olarak tanımlanabilir (Yıldız, 1989, s. 5).

İlimle dengeli tasarlanan yapı, kişi sağlığını olumlu yönde etkileyecektir. Sağlık yapılarında düşük enerji tüketimi ile etkin ve verimli alanlar oluşturabilmek için kullanım amacına uygun, optimum gereksinimleri karşılayan tasarımların yapılması son derece önemlidir. Ayrıca tüm gün kesintisiz hizmet verilen ve yüksek enerji tüketimi olan sağlık yapılarının iklimle dengeli tasarımı ile yapının performansının artacağı ve enerji yüküne yönelik maliyetlerin azalacağı açıktır (U.S. Department of Energy, 2009).

Yapılarda iklimsel konfor tasarım parametrelerini optimum seviyede karşılamak bir tasarım kararıdır. Bu karar, iklim unsurlarından en iyi şekilde yararlanmayı ve çevrenin olumsuz koşullarından yapıyı korumayı gerektirir. İklimle dengeli tasarımda, belirleyici olan parametreler 5'e ayrılmaktadır. Bunlar;

Yapının Konumu: Sağlık yapısının, bulunduğu iklimle dengeli şekilde tasarımının yapılmasında yer seçimi ve topografyaya uyum önemli bir etkendir. Yapı için önemli kriterlerden birisi olan yer seçimi ile birlikte çevredeki diğer yapılarla ilişkisi, güneşin yönlenişi, hakim rüzgarın yönü dikkate alınarak çevre ile uyumlu tasarımlar gerçekleştirilebilir.

Yapının Yönlendirilmesi: Yapının yönlendirilmesinde 2 temel ilke göz önünde tutulmalıdır. Bu ilkelerin ilki güneşten yararlanmanın kışın en yüksek seviyede, yazın da aynı oranda en düşük seviyede olmasının getirdiği koşullardır. Bir diğer ilke ise, doğal havalandırmanın gerçekleşmesi adına hakim rüzgar etkisinden yararlanmaktır (Demirtaş, 2011, s. 11).

Yapının Formu: Plandaki yapı uzunluğunun yapı derinliğine oranı, yapı yüksekliği, çatı türü, eğimi, cephe eğimi ve çıkıntıları gibi yapıyı oluşturan geometrik değişkenler ile tanımlanabilmektedir. 
Yapının Kabuğu: Yapı içi çevre ile yapı dışı çevreyi birbirinden ayıran öğe olarak tanımlanabilir. Yapıyı dışarıdan sarmalayan duvarlar ve çatı öğeleri, üzerindeki parça ve bileşenler ile birlikte yapının kabuğunu oluşturur. (Gedik, 2011, s.n.y). Yapı kabuğundaki opak ve saydam bileşenlerin oranının bölgenin iklim özellikleri dikkate alınarak tasarlanması ısı kayıp ve kazançlarında fazlasıyla etkili olmaktadır.

Yapının Yakın Çevredeki Yapılaşma Düzeniyle İlişkisi: Yapıların, kentsel alanlarda konumlanmasıyla, yapılaşmanın çok daha seyrek yapıldığı kırsal alanlara konumlanması iklimle dengeli tasarım için oldukça önemli farklılıklar gösterir. Yapılaşmanın yoğun olduğu kentsel alanlarda, hava hareket hızı düşük seviyede, hava sıcaklığı ise kırsal bölgeye oranla daha yüksek seviyede olabilir.

Parametrelerin optimum seviyede karşılanması, enerji kayıp ve kazançlarının en alt seviyeye indirilmesinde etkin bir rol oynamaktadır (Demirtaş, 2011, s. 11).

\section{MUŞ DEVLET HASTANESI'NIN IKLIMSEL KONFOR TASARIM PARAMETRELERI KAPSAMINDA DEĞERLENDIRILMESI}

Çalışma kapsamında, Türkiye'nin soğuk iklim bölgesindeki, Muş ilinde bulunan bir sağlık yapısı incelenecektir. Muş ili $39^{\circ} 29^{\prime}$ ve $38^{\circ} 29^{\prime}$ kuzey enlemleri ile $41^{\circ} 06^{\prime}$ ve $41^{\circ}$ 47' doğu boylamları arasında, doğudan Ağrı'nın Patnos ve Tutak ilçeleri, Bitlis'in Ahlat ve Adilcevaz ilçeleri, kuzeyden Erzurum'un Karayazı, Hınıs, Tekman ve Karaçoban ilçeleri, batıdan Bingöl'ün Karlıova ve Solhan ilçeleri, güneyden ise Diyarbakır'ın Kulp, 4 Batman'ın Sason, Bitlis'in Güroymak ve Mutki ilçeleri ile çevrilidir. Doğu Anadolu Bölgesinin Orta Fırat Havzası içinde yer alan ilin yüzölçümü $8.196 \mathrm{~km}^{2}$ dir (daka.org, 2011, s. 3-4). Bölge dağlık bir alandır. Ayrıca bölgede vadi, plato ve ovalar vardır.

Muş iline ait Meteroloji Genel Müdürlüğü'nden alınan 1963-2016 yılları arasını kapsayan iklim verileri incelendiğinde, ortalama sıcaklığın $9,8{ }^{\circ} \mathrm{C}$ olduğu, ildeki en yüksek sıcaklığın $33,1^{\circ} \mathrm{C}$ ile Ağustos ayında, en düşük sıcaklığın ise $\quad-11^{\circ} \mathrm{C}$ ile Ocak ayında gerçekleştiği görülmektedir. Ortalama yıllık yağış miktarının $764,5 \mathrm{~mm}$ olduğu, en çok yağışın Nisan ayında, en az yağışın ise Ağustos ayında gerçekleştiği görülmektedir. Yıllık ortalama rüzgâr hızının 1,40 m/sn olduğu, en hızlı esen rüzgârın Ocak ayında kuzey - kuzeybatı yönünde estiği görülmektedir (mgm.gov.tr, 2018).

Çalışma kapsamında incelenen Muş Devlet Hastanesi bölgesel olarak Muş ilinin merkezinde yer almaktadır. Sağlık yapısının da bulunduğu bölgedeki hakim rüzgar yönü kuzey ve kuzeybatıdır. Hastanenin kent içi konumu (Şekil 1)'de gösterilmiştir.

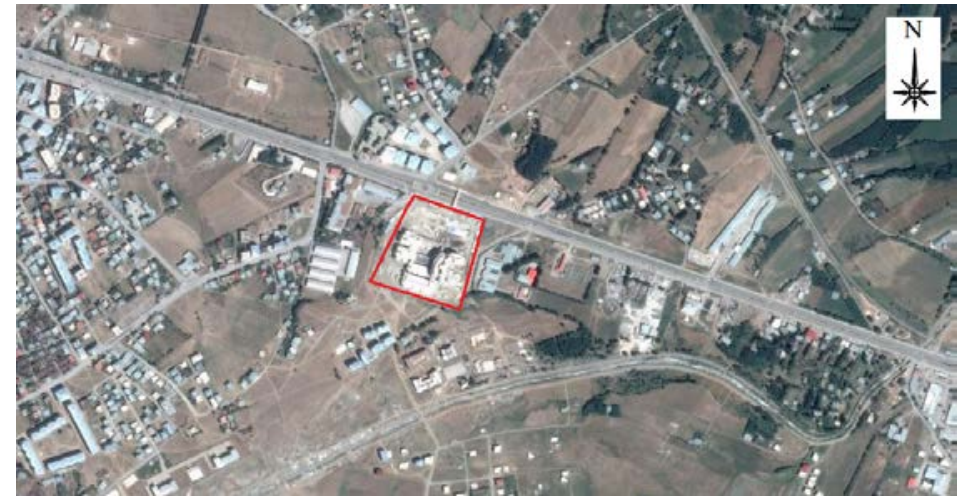

Şekil 1: Muş Devlet Hastanesi Kent İçi Konumu 
Muş Devlet Hastanesi 1. Mıntıka Mahallesi, 543 ada, 1 parselde bulunmaktadır. Hastanenin ihalesi 2010 yılında tamamlanmıştır. İnşaatın tamamlanması ile sağlık tesisinin 2014 yılında geçici kabul işlemleri de yapılarak hizmete açılmıştır. Hastane 300 yatak kapasitesine sahiptir. Ayrıca hastanenin bulunduğu parsel alanı 47.234 ve toplam inşaat alanı $55.625 \mathrm{~m}^{2}$ 'dir. Proje tasarımı Aymaz Mimarlık, fotoğraf çekimleri müşavir firma Prokon ile Beşer Ortaklığı tarafından yapılan Muş Devlet Hastanesi için oluşturulmuş inceleme künyesi (Şekil 2)'de gösterilmiştir.

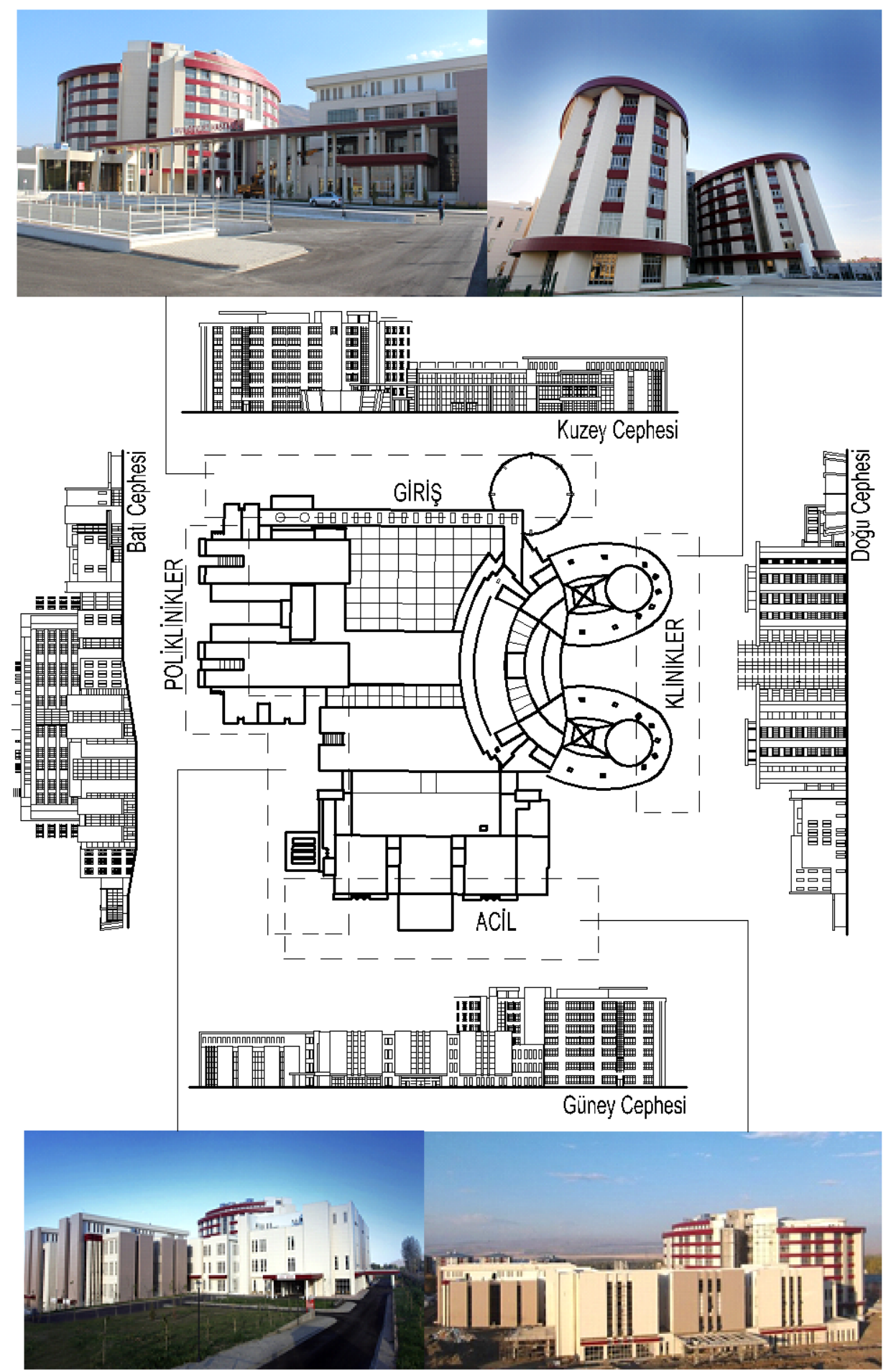

Şekil 2: Muş Merkez Devlet Hastanesi İnceleme Künyesi 
Yapılan araştırmalarda, enerji etkinliğini sağlamada ısı kayıplarının önlenebilmesi için saydam bileşenlerin oranının \%40'ın üzerinde olmaması gerekliliği vurgulanmıştır. (Demir, 2017, s. 36). Muş Devlet Hastanesi için, yapı kabuğu bağlamında opak ve saydam bileşenlerin durumu incelendiğinde $14.630 \mathrm{~m}^{2}$ alan kapladığı görülmektedir. Bunun $6.782 \mathrm{~m}^{2}$ 'sini saydam bileşenler oluşturmaktadır. Yüzde olarak ifade etmek gerekirse, saydam bileşenlerin toplam yapı cephesine oranının \% 46 olduğu görülmektedir. Detaylı olarak her bir cephenin dağılımı incelendiğinde, ana giriş kapısının da bulunduğu kuzey cephesindeki saydamlık oranı \% 45,62, diğer cephelerin sırasıyla, batı cephesi \% 38,40, doğu cephesi \% 47,90, güney cephesi \% 55,76'dır. (Çizelge 2)'de opak ve saydam bileşenlerin kapladığı $\mathrm{m}^{2}$ ve yüzde olarak dağılımı detaylı olarak belirtilmektedir.

Çizelge 2: Opak ve Saydam Bileşenlerin Dağılımı

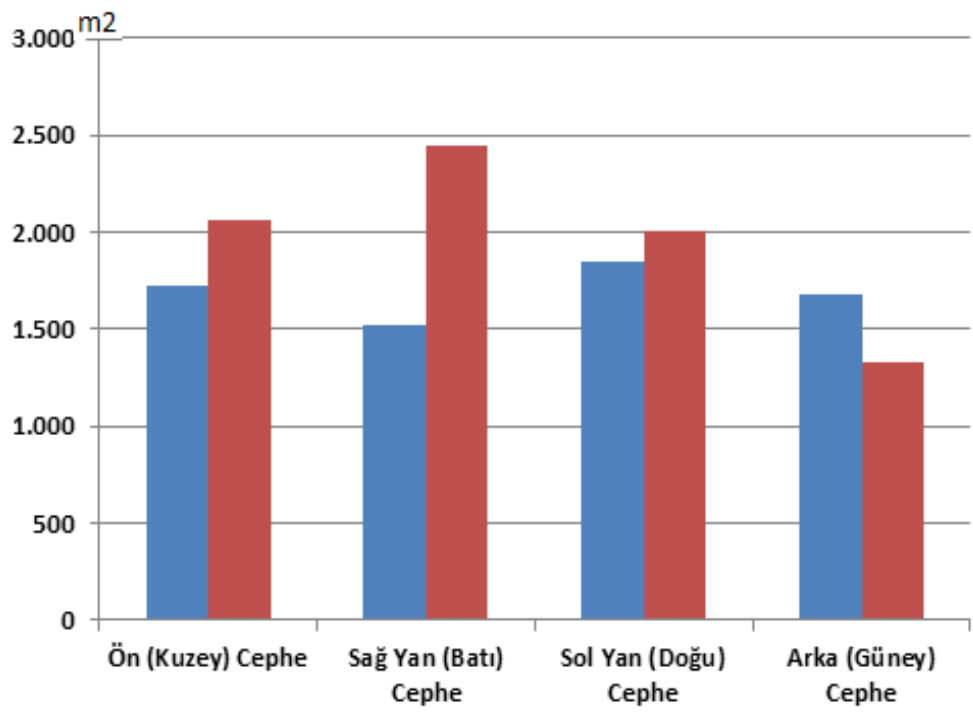

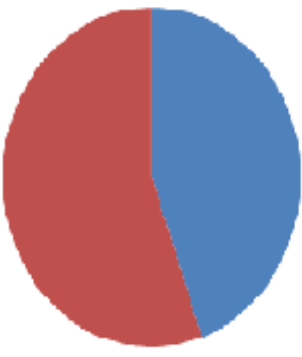

- Saydam opak

\begin{tabular}{|c|c|c|}
\hline Muṣ Merkez Dev let Hastanesi & Saydam Bileșenler (m2) & Opak Bileșenler (m2) \\
\hline Ön (Kuzey) Cephe & 1.729 & 2.061 \\
\hline Sağ Yan (Batı) Cephe & 1.526 & 2.447 \\
\hline Sol Yan (Doğu) Cephe & 1.845 & 2.006 \\
\hline Arka (Güney) Cephe & 1.682 & 1.334 \\
\hline Toplam & 6.782 & 7.848 \\
\hline
\end{tabular}

Ayrıca, cephede opak kısımlarda $8 \mathrm{~mm}$ kompakt laminant kaplama, saydam kısımlarda 4+12+4 ısıcamlı alüminyum giydirme kullanıldığı ve çatıda teras çatı uygulamasının suni mermer karo malzeme ile yapıldığı görülmektedir. Projede tasarım aşamasında, bölgenin iklim özellikleri ve imalatın gereklilik düzeyine yeterince bakılmaksızın uygulanan geniş saydam yüzeyler, teras çatı uygulaması, hakim rüzgar yönünde ana giriş kapısı dikkati çekmektedir. Ayrıca imalatlara ait mimari detay projeleri bulunmaması bir diğer olumsuz durumdur. Uygulama aşamasındaki fotoğraflar (Fot.1) ve (Fot.2)'de, hakim rüzgâr yönündeki geniş saydam yüzeyli ana giriş kapısı (Fot.3)'de gösterilmektedir. 


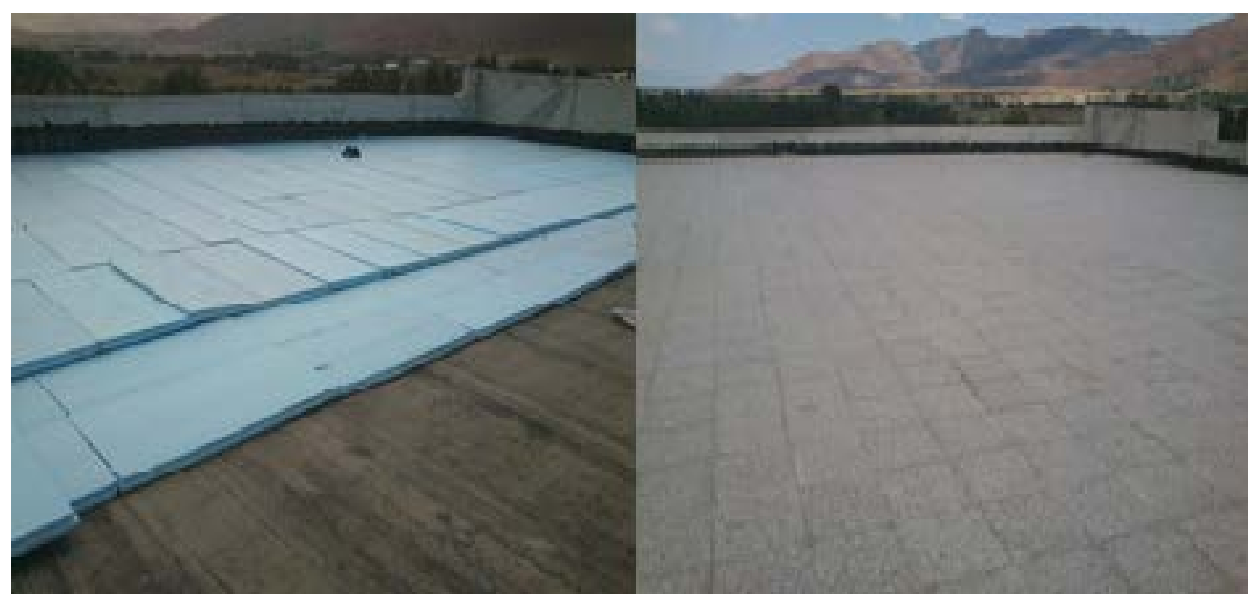

Fot.1: Teras çatı izolasyonu ve suni mermer karo ile kaplanması (Prokon\&Beşer Ortaklığı, 2012)

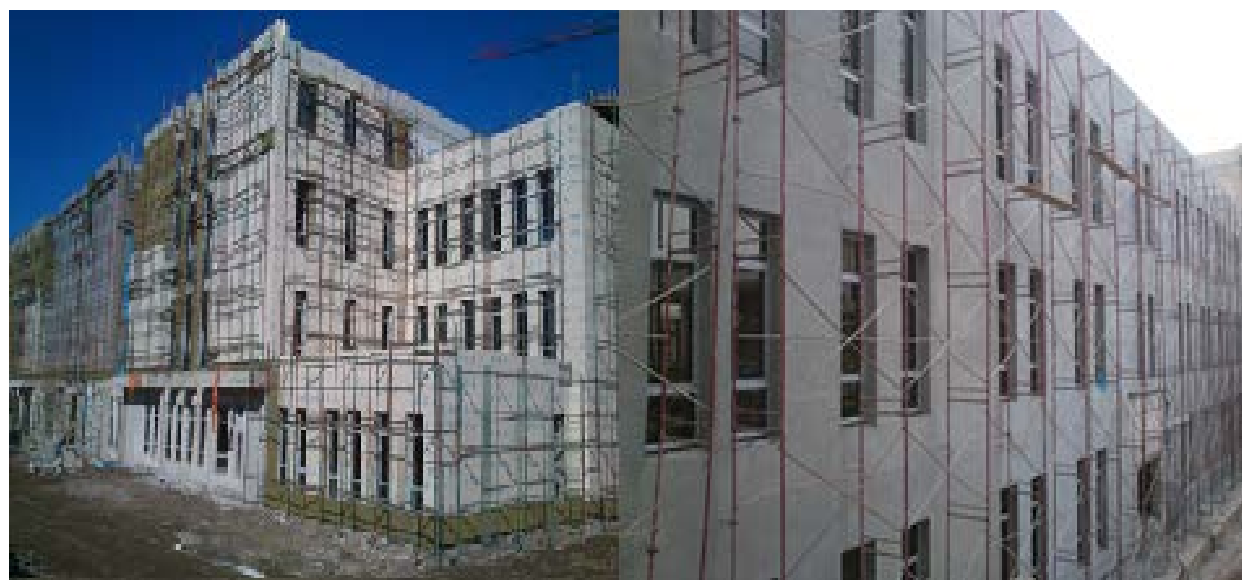

Fot.2: Taş yünü dış cephe mantolama ve kompakt laminant kaplama (Prokon\&Beşer Ortaklığı, 2012).

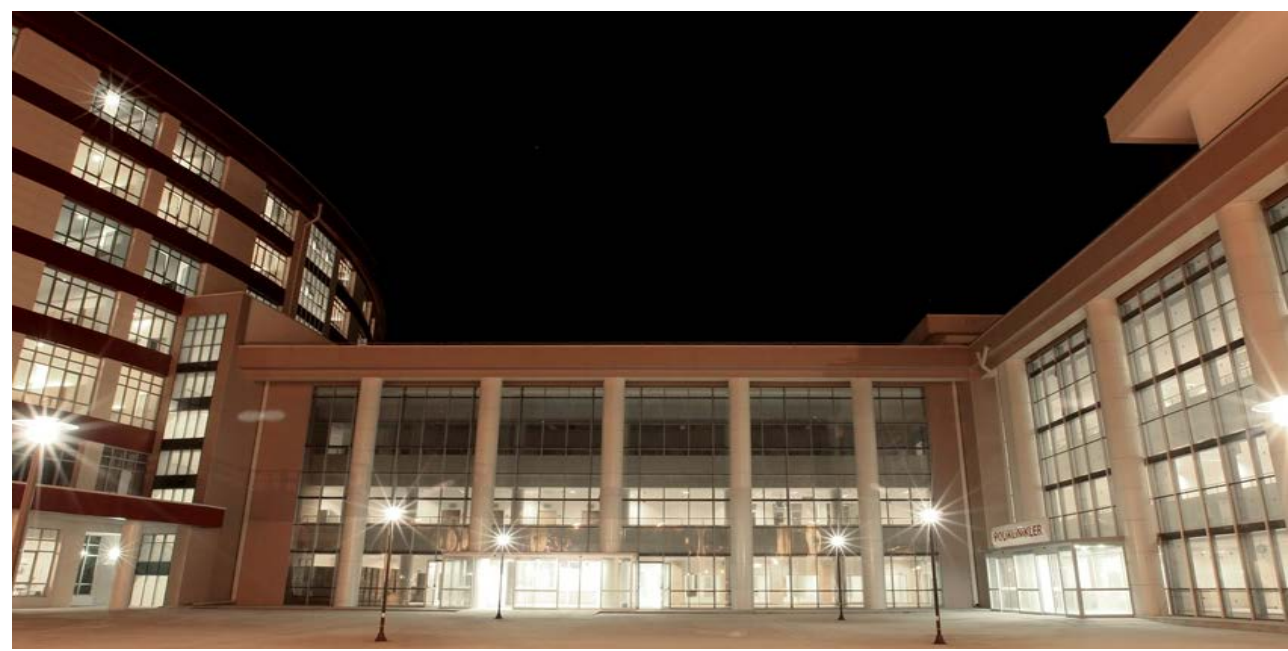

Fot.3: Hakim rüzgar (kuzey) yönünde konumlanan ana giriş kapısı ve geniş saydam yüzeyler (Prokon\&Beşer Ortaklı̆̆ı, 2013).

Muş Devlet Hastanesi'nin iklimsel konfor tasarım parametrelerine göre ve her bir parametre için ayrı ayrı olmak üzere değerlendirmesi (Çizelge 3)'de detaylı olarak açıklanmıştır. 
Çizelge 3: Değerlendirme/ Muş Devlet Hastanesi

\begin{tabular}{|c|c|c|}
\hline $\begin{array}{l}\text { Paramet } \\
\text { reler }\end{array}$ & $\begin{array}{l}\text { Sağlık Yapısının } \\
\text { Mevcut Durumu }\end{array}$ & Değerlendirme \\
\hline 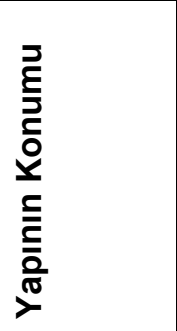 & $3^{\circ}$ eğimli arazi ve & $\begin{array}{l}\text { Berköz E. sıcak nemli iklimsel bölge için yapının en fazla } 24^{\circ} \text { ye } \\
\text { kadar olan eğimli arazide ve yamacın alt kısmında konumlanması } \\
\text { gerekliliği vurgulanmıştır (Berköz ve diğ., 1995, s. 25-26) } \\
\text { Muş Devlet Hastanesi } 3^{\circ} \text { eğimli arazide ve yamacın alt kısımlarında } \\
\text { konumlanmasıyla optimum kriterleri karşılamaktadır. } \\
\text { Değerlendirmenin sağlıklı yapılabilmesi için sağlık yapısının yer } \\
\text { seçiminde üst ölçekli planlarda tanımlanan donatı alanları (sağlık } \\
\text { donatısı) içerisinde yer alıp almadığının bilinmesi yararlı olacaktır. }\end{array}$ \\
\hline 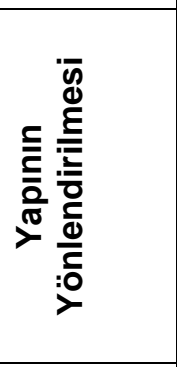 & & $\begin{array}{l}\text { Zeren L. ve Özdemir B. soğuk iklimsel bölge için yapının } 22^{\circ} \text { güney } \\
\text { doğu yönünde yönlendirilmesinin optimum durumu ifade ettiğini, } 31^{\circ} \\
\text { güneybatı ve } 86^{\circ} \text { güneydoğu aralığında yönlendirilmesinin de yeterli } \\
\text { durumu ifade ettiğini vurgulamıştır (Zeren, 1977, s.15; Özdemir, } \\
2005 \text {, s. 45) } \\
\text { Muş Devlet Hastanesi } 15^{\circ} \text { kuzeydoğu yönünde yönlendirilmiştir. } \\
\text { Dolayısıyla optimum kriterleri karşılamaktan oldukça uzaktır. }\end{array}$ \\
\hline 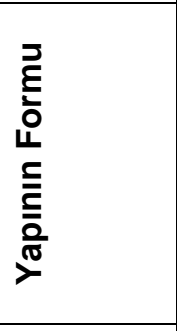 & & $\begin{array}{l}\text { Olgvay V. ve Zeren L. soğuk iklimsel bölge için yapının formunun ısı } \\
\text { kaybının az olması için düşük yüzey alanlı kompakt yapı biçiminde } \\
\text { olması gerekliliği vurgulanmıştır (Zeren ve diğ., 1990, s. 60; Olgvay, } \\
\text { 1992, s. 89) } \\
\text { Muş Devlet Hastanesi serbest formda tasarlanmıştır ve tasarım } \\
\text { olabildiğince yüzey alanının arttırılmasına (girintiçıkıntı) yönelik } \\
\text { gerçekleştirildiği için ısı kaybı ve detay problemi ciddi olumsuzlukları } \\
\text { içerebilir. }\end{array}$ \\
\hline 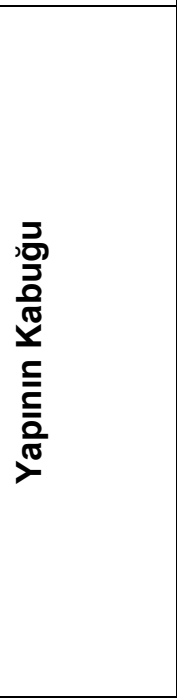 & $\begin{array}{l}\text { Açık renk duvarlar, dış } \\
\text { duvarda büyük } \\
\text { pencereler, kuzeydoğu } \\
\text { yönünde rüzgara açık } \\
\text { kapı konumu ve düz } \\
\text { çatı } \\
\text { Kullanılan malzemeler: } \\
\text { Alüminyum doğramalı } \\
4+12+4 \text { çift cam, } \\
\text { alüminyum doğramalı } \\
4+12+4 \text { temperli } \\
\text { reflekte ısıcamlı } \\
\text { giydirme cephe } \\
\text { kaplaması, kompakt } \\
\text { laminant giydirme } \\
\text { cephe kaplaması. }\end{array}$ & $\begin{array}{l}\text { Zeren L. soğuk iklimsel bölge için yapı kabuğunun ıSı depolama } \\
\text { kapasitesi fazla koyu renk masif duvarlar, küçük pencereler, } \\
\text { rüzgâra kapalı kapı konumu ve yüksek derecede eğimli çatı olması } \\
\text { gerekliliğini vurgulanmıştır (Zeren ve diğ., 1990, s. 64-66). } \\
\text { Muş Devlet Hastanesi'nin açık renk duvarları, geniş pencereleri, } \\
\text { kuzeydoğu yönündeki rüzgâra açık ana giriş kapısı ve düz çatısı, } \\
\text { kriterlerin tam aksinin tasarlandığını göstermektedir. Saydam } \\
\text { kısımlarda } 4+12+4 \text { reflekte temperli ısıcam ile ısı kontrolü için } \\
\text { önlem alınmaya çalışımıştır. Ancak malzeme kullanım kararları } \\
\text { yönlere bağlı olarak değişiklik göstermemektedir. Saydam } \\
\text { bileşenlerin yönlere bağlı dağııımı da bölge için uygun değildir. } \\
\text { Sağlık yapısının yönlere göre opak ve saydam bileşenlerin dağıımı } \\
\text { (Çizelge 2)'de gösterilmiştir. Ayrıca, tüm cephelerdeki saydamlık } \\
\text { oranı \%46'dir. Bölge için uygun olmadığı düşünülmektedir. Sağlık } \\
\text { yapısının avan proje ile proje ihalesi yapılımıştır. Malzeme detayları, } \\
\text { kesit çizimleri bulunmamaktadır. }\end{array}$ \\
\hline 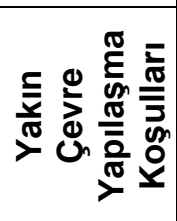 & $\begin{array}{c}\text { Plansız seyrek düzen } \\
\text { yapılaşma }\end{array}$ & $\begin{array}{l}\text { Zeren L. ve Berköz E. çalışmalarında soğuk iklimsel bölge için } \\
\text { bitişik düzen yapılaşmanın uygunluğu belirtilmiştir (Zeren, 1977, s. } \\
\text { 21-22; Berköz ve diğ., 1995, s. 38-40). } \\
\text { Muş Devlet Hastanesi'nin yakın çevresinde yapılaşma seyrektir ve } \\
\text { bölge için uygun değildir. }\end{array}$ \\
\hline \multicolumn{3}{|l|}{ LEJANT } \\
\hline
\end{tabular}




\section{DEĞERLENDIRME VE SONUÇ}

Teknolojinin gelişimi ve hızıı nüfus artışı enerji tüketiminin de artmasına neden olmaktadır. Dünyada toplam enerjinin \% 40'ı yapılardan kaynaklı tüketilmektedir (European Commission, 2006). Yenilenemeyen kaynaklardan elde edilen enerji ve harcamalardaki artış ile birlikte enerji kaynakları her geçen gün azalmaktadır. Sağlık Bakanlığı'nın hazırlamış olduğu "Sağlıkta Dönüşüm Projesi" ile birlikte kaynakların etkin ve verimli kullanımı hedeflenmiş olsa da, iklimsel bölgelere yönelik kaygıların göz ardı edildiği tasarım anlayışını barındıran soğuk iklimsel bölgede bulunan Muş Devlet Hastanesi'nin sorgulanması ve değerlendirilmesi amaçlanmıştır.

Avrupa'da iklimle dengeli tasarlanmış bir yapının ısıtılması için tüketilen enerjinin, bölgenin iklim özellikleri dikkate alınmadan tasarlanan yapılarla karşılaştırması yapıldığında, enerji tüketiminin 10 kat daha az olduğu hesaplanmıştır (Spagnolo ve Dear, 2003, s. 725). Enerji harcamalarında oldukça önemli bir paya sahip olan sağlık yapılarının tasarım aşamasında alınacak kararlar ile sürdürülebilir yapılar olarak iklimle dengeli tasarlanması hedeflenmelidir. Bu bağlamda, iklimsel konfor koşullarının sağlandığı tasarım parametrelerinin benimsenerek, yapının konumu, yönlendirilişi, biçimi, kabuğu ve yakın çevre yapılaşma koşullarıyla uygun seçeneklerin belirlenmesi gerekmektedir.

Ayrıca iklimsel konfor tasarım parametrelerine ek olarak,

- Değerlendirmenin sağlıklı yapılabilmesi için sağlık yapılarının yer seçiminde üst ölçekli planlarda tanımlanan donatı alanları (sağlık donatısı) içerisinde yer alıp almadığının bilinmesi,

- Sağlık yapılarının yer aldığı alanın kentsel bağlam içindeki yeri, ulaşım ilişkileri ve topografik yapısının da yönlendirilmesindeki etkisinin bilinmesi,

- Sağlık yapılarının formunu hastane tipolojileri açısından değerlendirebilmek için iklimsel bölgelere yönelik kurumsal standartların oluşturulması,

- Sağlık yapılarının yapı kabuğu tasarımının uygulama detay projelerindeki malzeme kararlarının (yalıtım malzemesi kalınlığı, duvar kalınlığı, kaplama malzemeleri kalınlığı vd.) farklı iklimsel bölgelere bağlı olarak yönetmeliklerce tanımlanması ve standartların yönlere bağlı olarak tanımlanması,

- Sağlık yapılarının ileriye yönelik projeksiyonlardaki yakın çevresinin yapılaşma kararlarının üst ölçekli planlarda belirtilen tanımlar dışında politik kararlarla değiştirilmemesi, yararlı olacaktır.

Çalışma sonucunda, soğuk iklim bölgesinde bulunan "Muş Devlet Hastanesi" için her bir parametre değerlendirildiğinde;

- Yapının konumu parametresinde, bölgenin iklim özelliklerine uygun olacak şekilde, $0-6^{\circ}$ eğimli arazi içerisinde ve yamacın alt kısımlarına yerleştiği görülmüştür. Optimum koşulda konumlanan yapı yeterli düzeyde değerlendirilmiştir.

- Yapının yönlendirilmesi parametresinde, soğuk iklim bölgesi için optimum yönlenme güney yönüdür. $15^{\circ}$ kuzeydoğu yönünde yönlenen sağlık yapısının bölgenin iklim özellikleri dikkate alınmadan tasarlandığı görülmektedir. Optimum koşullardan uzak yönlenen yapı yetersiz düzeyde değerlendirilmiştir.

- Yapının formu parametresinde, soğuk iklim bölgesi için kompakt kareye yakın formların tercih edilmesi uygundur. Serbest formda tasarlanan sağlık yapısı, artan yüzey alanı ile 
(girinti-çıkıntı) son derece olumsuzlukları barındırmaktadır. Bu parametre için yetersiz düzeyde değerlendirilmiştir.

- Yapının kabuğu parametresinde, soğuk iklim bölgesi için ısı depolama kapasitesi fazla koyu renk masif duvarlar, küçük pencereler, rüzgâra kapalı kapı konumu, yüksek derecede eğimli çatı uygundur. Muş Devlet Hastanesi ısı depolama kapasitesi düşük açık renk duvarları, geniş pencereleri, hakim rüzgâr yönünde tasarlanmış rüzgâra açık ana giriş kapısı ve teras çatısı ile kriterleri karşılayamamaktadır. Bu parametre için yetersiz düzeyde değerlendirilmiştir.

- Yapının yakın çevredeki yapılaşma düzeniyle ilişkisi parametresinde, soğuk iklim bölgesi için yapıdaki ısı kayıplarının en az seviyede olmasını sağlayacak şekilde bitişik düzen yapılaşma uygundur. Sağlık yapısının yakın çevresindeki yapılaşmanın seyrek olduğu görülmektedir. Bu parametre için de yetersiz düzeyde değerlendirilmiştir.

Sonuç olarak, Muş Devlet Hastanesi yalnızca yapının konumu parametresini karşılayabilmiştir. Diğer parametreleri karşılamada ise başarısız ve yetersiz düzeyde değerlendirilmiştir.

Tasarım sürecinde ayrıntılı yapılmayan analizler ile bölgenin iklim koşulları göz ardı edilerek gerçekleştirilen oldukça geniş saydam yüzeyler, teras çatı gibi uygulamalar yapının yanlış yönlenmesine neden olmakta ve enerjinin verimsiz kullanılması sonucunda büyük maliyet artışlarına yol açmaktadır. Optimum koşullar dikkate alınmadan tasarlanmış olan, hakim rüzgâr (kuzey) yönünde kurgulanmış ana giriş kapısı dikkat çekmektedir. Ayrıca, saydam bileşenlerin hemen hemen her cephede birbirine yakın oranlarda tasarlanması projede dikkat çeken bir diğer husustur. Oysaki yapı kabuğunda bulunan opak ve saydam bileşenlerin tüm yönlerde doğru oranlarda tasarlanması enerji etkin yapının elde edilmesinde temel bir koşuldur.

Sağlık yapıları gibi yüksek enerji harcayan binalarda, konuya daha hassas ve sağlık hizmeti ile işletme maliyetini düşünerek yaklaşmak ve en azından saydam yüzeyleri bölgenin iklim özelliklerini düşünerek ve içerideki işlev ve hizmet ile bir bütün olacak şekilde planlayarak tasarlamak gerekir. Ayrıca, Sağlık Bakanlığı Karar Destek Sistemi içerisinde bulunan Enerji Takip Modülü 2017 verileri incelendiğinde Muş Devlet Hastanesi'nin 2017 yılındaki yıllık elektrik ve yakıt tüketim maliyetleri toplamı 3.737.694 TL'dir. Belirlenen iklimsel konfor tasarım parametreleri, ilgili kurumsal yapıların yasal ve yönetsel tanımlamalarıyla sağlıklı bir aşamada değerlendirilmesi gereken bir çözümdür. Sağlık yapılarının tasarım kararlarının bu parametrelerdeki optimum düzeyde olması Türkiye'nin enerji giderlerini önemli ölçüde azaltacak, enerji etkin, sürdürülebilir ve iklimle dengeli, konforlu çevreler yaratılmasını sağlayacaktır.

Sağlık Bakanlığı nezdinde hazırlatılan mimari projelerde, Bakanlık ilgili birimi tarafından gerçekleştirilecek düzenlemeler ve proje-yapım süreçlerini bir sisteme oturtacak tüm idari ve teknik çalışmaların standardizasyonu sağlanmalıdır. Bunun yanı sıra, enerjinin verimliliğine ilişkin tüm iklimsel konfor parametreleri ile yapım teknikleri ve güncel uygulamalar da takip edilerek sağılk yapıları gibi karmaşık işlevli ve yüksek enerji tüketilen yapı tiplerinde ivedilikle hayata geçirilmelidir.

Bu çalışma ile sağlık yapılarının enerji maliyetlerinin düşürülmesi için tasarım aşamasında alınabilecek önlemlerin önemine dikkat çekilmek istenmiştir. Sınırsız kaynaklara sahip olmayan çevre bilinci kurumsal politika olarak benimsenerek, bölgesel farklılıkların göz ardı edilmediği, iklimle dengeli tasarımların hayata geçmesinin önemi vurgulanmaktadır. 


\section{KAYNAKLAR}

Bednarz, D., Rising energy costs and the future of hospital work. Energy Bulletin, New York 2008.

Berköz, E., Küçükdoğdu, M., Yılmaz Z. vd., "Enerji Etkin Konut ve Yerleşme Tasarımı", Tübitak-İntag 201, Araştırma Raporu, İstanbul 1995, s. 25-40.

Bilec, M. M., Geary, R. J. Ries, K. L. Neddy ve M. Badpa ve M. Azmal, Evaluation of Hospital Dimensions in Teaching and Private Hospitals Covered by Tehran University of Medical Sciences, Journal of Service Science and Management, Cilt 22 (3), Tehran 2015, s. 3-11.

Carpenter, D. ve Hoppszallern, S., Sustainable operations survey: green and greener: hospitals embrace environmentally sustainable practises, though laggards remain. Health Facilities Management Magazine, Cilt 23(7), New York 2010, s. 15-21.

Demir, Seda, Ilıman Nemli İklim Bölgesi İçin Tasarlanan Konut Yapısında Değişken Yapı Kabuğu Performansının Değerlendirilmesi, Yüksek Lisans Tezi, YTÜ Fen Bilimleri Enstitüsü, İstanbul 2017.

Demirtaş, Ayşe, Farklı İklim Bölgelerinde Otel Yapılarının Isıtma ve Soğutma Yükleri Açısından Karşılaştırılması, Yüksek Lisans Tezi, YTÜ Fen Bilimleri Enstitüsü, İstanbul 2011.

Doğu Anadolu Kalkınma Ajansı, Coğrafi Konum ve İklim Verileri, http://www.daka.org.tr/panel/files/files/yayinlar/TRB2 Bolgesi MDA CografiKonumvelklim 2 011.pdf,0 18 Mart 2018

European Commission 2006, Saving \%20 By 2020, https://ec.europa.eu, 20 Mayıs 2018

Gedik, Gülay Zorer, "Soğuk Iklım Bölgesinde Yalıtımlı Yapı Kabuğu Kesitlerinin İncelenmesi ve Değerlendirilmesi: Erzurum Örneği” YTÜ Mimarlık Fakültesi Yapı Fiziği Bilim Dalı, İstanbul 2011, s.n.y.

Google Earth, Muş, https://earth.google.com/web/, 10 Nisan 2018

Hoşgör, Haydar, "Yeşil Hastane Konsepti ve Türkiye Deneyimi", Sağlık Bilimleri ve Meslekleri Dergisi Cilt, 1(2), Ankara 2014, s. 75-84.

İklim Verileri, Muş İli İklim Raporu, https://tr.climate-data.org/location/277I, $\quad 26$ Ocak 2018 Metoroloji Genel Müdürlüğü, İllerimize Ait İstatistik Veriler, https://www.mgm.gov.tr/veridegerlendirme/il-ve-ilceleristatistik.aspx?m=MUS, 18 Şubat 2018

Muş Merkez Devlet Hastanesi Cephe Görselleri, Prokon\&Beşer Ortaklığı.

Olgvay, Victor, "Bioclimatic Design With Climate", Aproach to Architectural Regionalizm, Newyork 1992, s. 89.

Özdemir, Banu Bahar, Sürdürülebilir Çevre İçin Binaların Enerji Etkin Pasif Sistemler Olarak Tasarlanması, Yüksek Lisans Tezi, îTÜ Fen Bilimleri Enstitüsü, İstanbul 2005. 
Paço, Armindo, Innovation in Public Health Care Institutions: The Case of Green Hospitals, in Handbook of Research on Global Competitive Advantage through Innovation and Entrepreneurship, PA: IGI Global, Hersey 2015, s. 339-351.

Royal Jubilee Hospital Patient Care Centre Project, Pacific Green, http://www.viha.ca/nr/rdonlyres/6339cbb7-e799-44fc-a15d

a91cddae0c9d/0/7410011pacificgreendefinedfinal.pdf, British Columbia 2008, 14 Nisan 2018

Somali, Berkay, Altensis: Yeşil Hastaneler Geliyor, http://faalenerjidergisi.com/haberdetayi. php?uid=293, İstanbul 2013b, 16 Nisan 2018 .

Somyürek, Umut, Sağlık Tesislerinde Enerji Verimliliği Analizinde Enerji Yoğunluğunun Kullanılması İle Yeni Yaklaşımlar Ve Yapılan Enerji Verimliliği Uygulamalarının Değerlendirilmesi, Denizli Kamu Hastaneleri Birliği Genel Sekreterliği, Denizli 2017.

Spagnolo, J., ve Dear, R., "A Field Study of Thermal Comfort in Outdoor and Semi- Outdoor Enviroments in Subtropical Sydney Australia", Building and Environment Cilt 38 (5), Australia 2003, s. 721-738.

T.C. Sağlık Bakanlığı, Karar Destek Sistemi, Enerji Takip Modülü, Ankara 2017.

T.C. Sağlık Bakanlığı, "Sağlıkta Dönüşüm Projesi Kapsamında Yapılacak Sağlık Tesisleri İçin Proje Aşamasında Uyulması Gereken Hususlar, 2012/6 Sayılı Genelge, T.C. Sağlık Bakanlığı", Ankara 2012.

T.C. Sağlık Bakanlığı, Sağlık İstatistikleri Yılığı 2016 Haber Bülteni, http:///C:/Users/\%C3\%96rge/Downloads/sb-2016 saglik-istatistikleri-yilligi.pdf,16 Nisan 2018

U.S. Department of Energy, Department of energy announces the launch of the hospital energy alliance to increase energy efficiency in the healthcare sector. U.S. Department of Energy Pres., http://energy.gov/articles/department-energy-announces-launch-hospitalenergy-alliance-increase-energy-efficiency, USA 2009, 14 Nisan 2018

WHO, Health Defination, http://www.who.int, 14 Nisan 2018

Yıldız, E., Bina İçi Çevre Mekanlarının İşlevine ve Bina Kabuğuna Bağlı İklimsel Konfor Açısından Yön Seçiminde Bir Yöntem, Doktora Tezi, ITÜ Fen Bilimleri Enstitüsü, İstanbul 1989.

Yıldız, Harun, "Sürdürülebilirlik Bağlamında Sağlık Sektöründe İnovatif Uygulamalar: Yeşil Hastaneler”, Kaüiibfd, Cilt 7 (13), Bandırma 2016 , s. 323-340.

Zeren, L., “Türkiye'de İklimle Dengeli Mimari Uygulama”, VI. Tübitak Bilim Kongresi, 17-21 Ekim 1977, Ankara 1977.

Zeren, L. ve diğ., Fiziksel Çevre Kontrolü Ders Notları, Fiziksel Çevre Kontrolü Birimi, İ.T.Ü., İstanbul 1990. 